\title{
Immunosuppression and Neuroinflammation in Stroke Pathobiology
}

\author{
Qian Jiang ${ }^{1,2}$, Christopher R. Stone ${ }^{3}$, Kenneth Elkin ${ }^{3}$, Xiaokun Geng ${ }^{1,2,3 *}$ and Yuchuan Ding ${ }^{3,4 *}$ \\ ${ }^{1}$ China-America Institute of Neuroscience, Beijing Luhe Hospital, Capital Medical University, \\ ${ }^{2}$ Department of Neurology, Beijing Luhe Hospital, Capital Medical University, Beijing 101100, China \\ ${ }^{3}$ Department of Neurosurgery, Wayne State University School of Medicine, \\ ${ }^{4}$ Department of Research \& Development Center, John D. Dingell VA Medical Center, Detroit 48201, MI, USA
}

\begin{abstract}
Over the preceding decades, there have been substantial advances in our knowledge of the pathophysiology of stroke. One such advance has been an increased understanding of the multifarious crosstalk in which the nervous and immune systems engage in order to maintain homeostasis. By interrupting the immune-nervous nexus, it is thought that stroke induces change in both systems. Additionally, it has been found that both innate and adaptive immunosuppression play protective roles against the effects of stroke. The release of danger-/damage-associated molecular patterns (DAMPs) activates Toll-like receptors (TLRs), contributing to the harmful inflammatory effects of ischemia/reperfusion injury after stroke; the Tyro3, Axl, and MerTK (TAM)/Gas6 system, however, has been shown to suppress inflammation via downstream signaling molecules that inhibit TLR signaling. Anti-inflammatory cytokines have also been found to promote neuroprotection following stroke. Additionally, adaptive immunosuppression merits further consideration as a potential endogenous protective mechanism. In this review, we highlight recent studies regarding the effects and mechanism of immunosuppression on the pathophysiology of stroke, with the hope that a better understanding of the function of both of innate and adaptive immunity in this setting will facilitate the development of effective therapies for post-stroke inflammation.
\end{abstract}

Key words: Innate immunity, Anti-inflammatory molecules, Adaptive immunity, Neuro-immunomodulation, Stroke

\section{INTRODUCTION}

Despite the status of stroke as one of the principal causes of death and disability worldwide, there is currently a paucity of treatments available to ameliorate its devastating effects $[1,2]$. Over 250 clinical trials have failed [3], suggesting that the discovery of efficacious treatments may require further investigation of the basic biology of stroke pathogenesis [4-6]. One promising focus of basic stroke science investigation is the field of stroke immunobiology.

Submitted August 3, 2020, Revised February 3, 2021,

Accepted February 23, 2021

* To whom correspondence should be addressed.

Xiaokun Geng, TEL: 010-69543901, FAX: 010-69543901

e-mail:xgeng@ccmu.edu.cn

Yuchuan Ding, TEL: 313-577-0038, FAX: 313-993-9269

e-mail:yding@med.wayne.edu
Ischemic stroke pathogenesis is complex, culminating in mitochondrial and DNA damage, release of reactive oxygen species, inflammation, and programmed cell death $[7,8]$. Several studies support the status of immune responses and inflammation as important factors in the pathogenic process: inflammation, initiated by stagnant blood flow, activation of intravascular leukocytes, and the release of pro-inflammatory mediators from the ischemic endothelium, has been shown to increase brain injury $[9,10]$. The immune system is involved in all stages of stroke. Local inflammatory responses mainly occur through activation of innate and adaptive immunity $[11,12]$. After an acute stroke, sensors of the innate immune system such as Toll-like receptors (TLRs) and innate immune cells, are activated by brain ischemia, leading to amplification of the inflammatory cascade. Subsequently, the adaptive immune system mediated by lymphocytes is activated and further amplifies the inflammatory response [13]. In particular, there is a
Copyright (c) Experimental Neurobiology 2021. www.enjournal.org
This is an Open Access article distributed under the terms of the Creative Commons Attribution Non-Commercial License (http://creativecommons.org/licenses/by-nc/4.0) which permits unrestricted non-commercial use, distribution, and reproduction in any medium, provided the original work is properly cited. 
growing body of evidence linking TLRs to the deleterious inflammatory effects of ischemia/reperfusion injury associated with stroke $[14,15]$. Moreover, the finding that genes responsible for innate inflammatory regulation comprise the majority of those acutely modulated in the post-stroke circulation suggests the importance of inflammation as an injury mechanism [16-18].

Research has demonstrated that immunoregulation may limit excessive inflammation after reperfusion. Inhibition of post-stroke inflammation, as exemplified by the effect of TAM/Gas6 signaling on the innate immune response promoted by TLRs [19], is recognized as a promising neuroprotective strategy. Additional innate immune-mediated protection against stroke is conferred by antiinflammatory molecules such as IL-1 receptor antagonist (IL-1Ra), IL-10, and TGF- $\beta$. IL-1Ra, for instance, not only limits brain injury by ischemic stroke, but also appears to confer benefit in patients with subarachnoid hemorrhage (SAH) [20-22]. Accordingly, both the TAM/Gas6- and cytokine-mediated pathways will be discussed in this review.

Following innate immune activation, inflammatory mediators produced in this initial response recruit the cellular effectors of the adaptive immune response. T-lymphocytes, in particular, play an integral role in the inflammatory response after stroke [23]. These, and the regulatory subset that has been implicated in neuroprotective immunosuppression, will also be discussed below after the initial section that describes the innate response.

Finally, a discussion of the neuro-immunomodulatory effects of the vagal cholinergic anti-inflammatory pathway, paired with a related discussion regarding the regulatory roles played by activation of the SNS and HPA axes, will conclude the review. Because neuroimmunomodulation negatively correlates with infarct volume [24], this pathway may represent an endogenous target for future pharmacologic neuroprotective strategies.

\section{POST-STROKE SUPPRESSION OF THE INNATE IMMUNE SYSTEM}

\section{TLRs and TAM/Gas6}

TLRs are transmembrane proteins composed of three structural domains: a leucine-rich repeats (LRRs) motif, a transmembrane domain, and a cytoplasmic Toll/IL-1 receptor (TIR) domain. Thus far, TLR1-TLR10 have been identified in humans [15]. Through the downstream actions of MyD88 and TRIF, these receptors have been shown to activate the innate immune response [25]. The TLR signaling pathway plays a crucial role in the pathogenesis of stroke [26]. TLR2 and TLR4 have been found to be especially important in this context: previous research has reported that these TLRs are widely expressed in the brain following cerebral ischemia, and may exacerbate tissue damage [27]. In a clinical study of ischemic stroke patients, it was reported that increased TLR2 and TLR4 expression was independently associated with poor functional outcome [28]. Recognition of this association may pave the way toward future therapies, as was illustrated by the same study in an in-vitro model of stroke, in which blocking TLR2 and TLR4 reduced the monocytic inflammatory response.

The TAM receptor class consists of three receptors: Tyro3, Axl, and MerTK. Growth arrest-specific gene 6 (Gas6) is a common ligand of these TAM receptors [29]. All three TAM receptors have similar extracellular domain structures, including two tandem N-terminal immunoglobulin-like domains (IGs) and two membrane-proximal fibronectin type III-like (FNIII) domains. TAM receptors and their ligands exert anti-inflammatory action and may be thought of as a countervailing force against the effects of TLRs [30]. TAM receptor activation may inhibit TLR activation and the associated signal transduction cascades, including those involving NF-KB and MAPK, and has been shown to inhibit the level of TLR-induced pro-inflammatory cytokines, such as TNF, IL-6, and IL-12 [31].

\section{TAM/Gas6-mediated immunosuppression}

As previously mentioned, TLRs are critical initiators of poststroke inflammation. They are activated by the release of danger-/ damage-associated molecular patterns (DAMPs), resulting in the production of pro-inflammatory mediators [15]. Activation of TLRs initiates signal transduction cascades that involve kinases, including the transcription factors activator protein-1 (AP-1) and NF- $\mathrm{kB}$, which induce the expression of inflammation-associated molecules and cytokines [32]. To avoid cerebral damage secondary to chronic inflammation, the TLR signaling pathway must be tightly regulated. Recent studies have demonstrated that TAM receptors act as innate immune system regulators by inhibiting the TLR-mediated pro-inflammatory response [30], and they have been identified as a potential therapeutic target in the setting of stroke [33].

Under both physiological and pathological conditions, TAM receptors are widely expressed in cells of the immune and nervous systems $[34,35]$. The level of TAM receptor expression is significantly increased after birth and remains high in adults, suggesting the importance of these receptors in normal physiology. This was further confirmed by a study of TAM knockout mice, in which peripheral lymphoid organs began to enlarge three weeks after birth. The spleens and lymphoid cell populations of these mice demonstrated excessive proliferation at 6 months, resulting in an imbalanced immune response [36]. The negative immunoregulatory mechanism of TAM receptors proceeds through downstream 
signaling cascades involving SOCS1 and SOCS3 E3 ubiquitin ligases. These, in turn, inhibit inflammatory responses mediated by regulatory signaling molecules such as TLRs and NF-kB [37]. TAM receptors are critical to the maintenance of immunohomeostasis: excessive inflammation mediated by the TLR signaling pathway would upregulate TAM/Gas6, yielding a TAM-initiated damping of TLR inflammatory signaling. In addition, the function of TAM receptor signaling has been demonstrated in central nervous system physiology. Tyro3, Axl, and MerTK are involved in the early development of the nervous system [38]. They have also been linked to CNS pathophysiology: the endogenous expression of Gas6 and Axl decreased significantly $24 \mathrm{~h}$ after middle cerebral artery occlusion (MCAO), and recombinant Gas6 reduced brain injury and inhibited the TLR/TRAF/NF-kB pathway [39].

Microglia, which act as resident macrophages within the central nervous system and are known mediators of neuroinflammation [40], express cytokine receptors, such as TLRs [41].Activation of microglia results in neuronal damage through the release of proinflammatory cytokines. Several reports have shown that TAM receptors may regulate the function of microglia [42]. Microglia express all three TAM receptors [43], and microglial neuroinflammation is subject to inhibition by the TAM/Gas6 system, which has been shown to maintain the cells phagocytic ability while inhibiting LPS-induced IL- $1 \beta$ expression. A recent study showed how this pathway may be exploited in stroke therapy [39]. Further evidence comes from studies that have investigated microglial function in the context of TAM signaling deficiencies. For instance, microglia lacking TAM receptors were found to produce a large number of proinflammatory cytokines after activation [43]. Additionally, deficient activity of both Axl and MerTK was found in adult mice to result in reduced microglial activity and impaired apoptotic cell clearance [42]. Finally, MerTK expression was found to be stimulated by immunosuppressive drugs, such as dexamethasone [44]. Taken together, this body of research suggests that TAM receptors participate in the negative regulation of microglial innate immune responses.

Astrocytes represent another type of immunomodulating cell capable of producing inflammatory neurotoxic mediators [45]. They have been shown to exhibit strong expression of Tyro3 and Axl, along with low expression of the MerTK receptor [46]. Analogous to the aforementioned microglia research, TAM-deficient astrocytes were found to release higher levels of IL- 6 after LPS activation than was observed in wild type (WT) counterparts. Additionally, TAM-deficient astrocytes produced a stronger IL-1 $\beta$ expression response to pro-inflammatory stimulation, than WT cells [45] (Fig. 1).

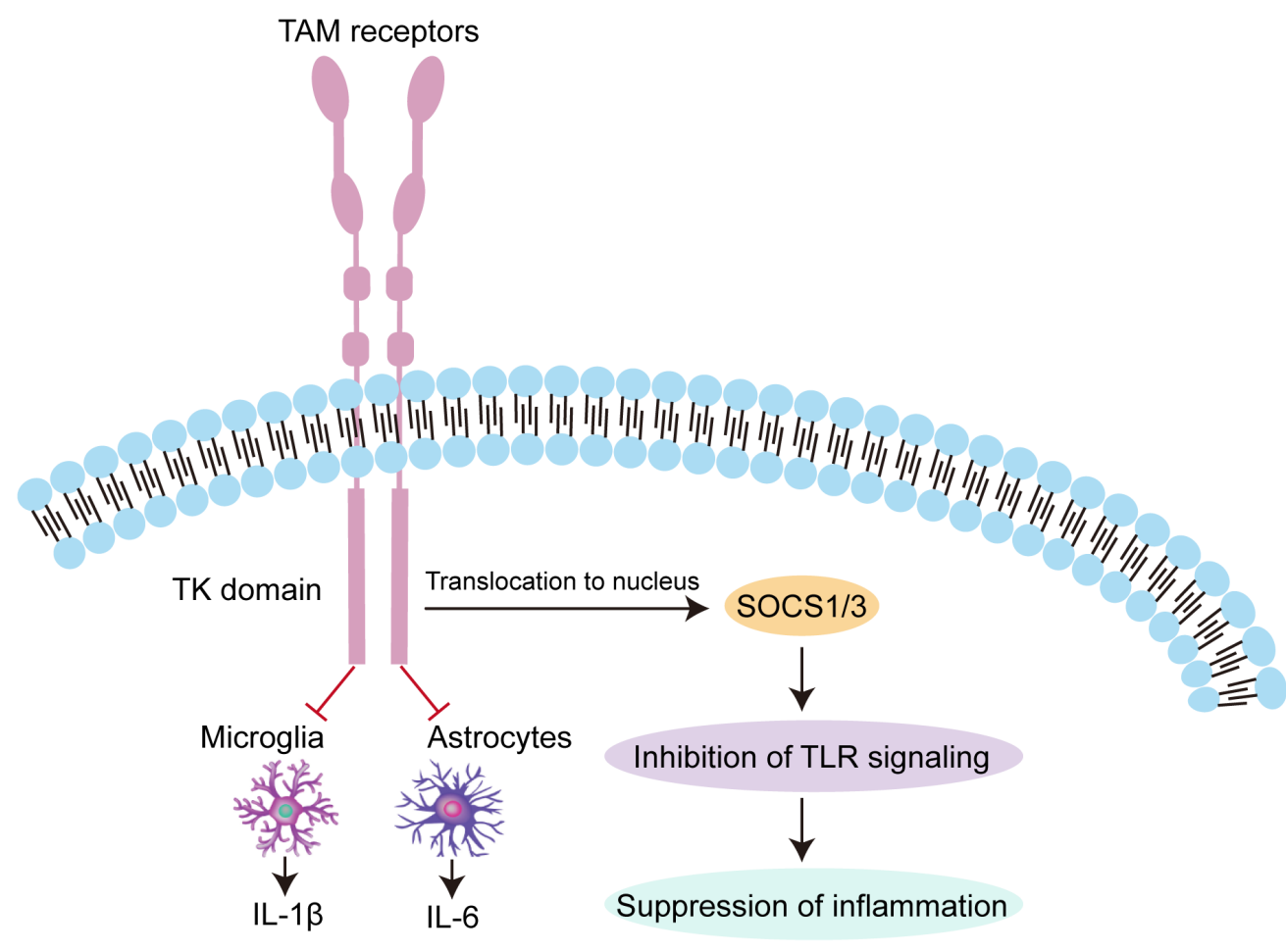

Fig. 1. Anti-inflammatory effect of TAM receptors. The negative immunoregulatory mechanism of TAM receptors proceeds through downstream signaling cascades involving SOCS1 and SOCS3 E3 ubiquitin ligases. These, in turn, inhibit inflammatory responses mediated by regulatory TLR signaling. TAM receptors can also decrease expression of IL- $1 \beta$ and IL- 6 via negative regulation of microglial and astrocytic activation. 


\section{POST-STROKE MEDIATORS OF THE ANTI-INFLAMMATORY RESPONSE}

\section{IL-1 receptor antagonist}

IL-1 is an important pro-inflammatory mediator of brain injury, and its inhibition has yielded neuroprotective efficacy in experimental models over the past two decades [47, 48]. There is a growing body of evidence indicating that rapid up-regulation of the two principal IL-1 ligands, IL- $1 \alpha$ and IL-1 $\beta$, occurs after stroke $[49,50]$. Recently, a third ligand was discovered, and found to be a competitive antagonist: IL-1 Ra [51]. This antagonist has been investigated in the context of subarachnoid hemorrhage: Greenhalgh et al. [52] reported that IL-1Ra is beneficial in a rat SAH model, and a phase II randomized controlled trial further demonstrated that IL-1Ra is safe for SAH patients. In the latter study, IL-1Ra was found to cross the blood-brain barrier (BBB) and appeared to decrease (albeit not to a degree that reached statistical significance) the concentration of IL-6, an inflammatory marker and downstream product of IL-1, in the cerebrospinal fluid (CSF) [53]. The therapeutic potential of IL-1Ra was also demonstrated in a mouse model of ischemic stroke, in which increased expression of IL-1Ra in leukocytes conferred neuroprotection [21]. These findings were echoed by another recent experiment by Pradillo et al. [54], in which IL-1Ra administration reduced ischemic brain injury in rats. In humans, intravenous IL-1Ra has been found in Phase II trials to be safe for use in ischemic stroke [55]; additionally, a recent Phase II trial of subcutaneous IL-Ra in ischemic stroke patients demonstrated reductions in inflammatory markers associated with poor acute post-stroke outcome [56].

\section{IL-10 and TGF- $\beta$}

Like IL-1Ra, IL-10 acts in the context of brain injury as an anti-inflammatory cytokine, promoting neuronal survival and suppressing inflammatory responses by producing inhibition at a number of steps in cytokine signal transduction, including cytokine synthesis, cytokine receptor expression, and cytokine receptor activation $[57,58]$. It is mainly produced by astrocytes and microglia $[59,60]$. The protection conferred by this cytokine against ischemic brain damage is illustrated by an experiment that compared response to permanent MCAO between IL- $10^{-/}$mice and wild-type mice. Compared with the latter, knockout mice had $30 \%$ larger infarct volumes $24 \mathrm{~h}$ post-stroke [61]. Similarly, IL-10 has been reported to improve neurological outcomes and limit infarct volume in experimental stroke [62, 63], while IL-10 polymorphisms have been implicated in increased susceptibility to stroke [64]. A study that employed intracerebroventricular injection in a mouse ischemic stroke model highlighted the genetic component of the effects of IL-10, showing that this method produced downregulation of over 300 genes that were upregulated by ischemia; moreover, most of these genes were associated with inflammation [65]. Additionally, several epidemiologic studies have demonstrated a relationship between IL-10 and ischemic stroke risk. A study in a south Indian population, for instance, showed that possession of the A allele of the IL-10 promotor SNP rs1800896, which is associated with low IL-10 production, conferred an increased risk of ischemic stroke [66]. Another study, in this case of a population of Eastern Finnish origin, found that plasma IL-10 correlated with high-risk sources of cardioembolic stroke, which suggested its utility in improving identification of stroke etiology [67].

TGF- $\beta$ is another neuroprotective and anti-inflammatory mediator that shows promise as an effective therapeutic agent in stroke. TGF- $\beta$ is mainly produced by astrocytes and microglia. Like IL10, blocking TGF- $\beta$ exacerbates brain damage [68], while TGF- $\beta$ overexpression leads to a decreased inflammatory response and reduced brain injury in mice following MCAO [69]. In rats, TGF- $\beta$ antagonism can aggravate brain damage caused by focal cerebral ischemia [16]. Pretreatment with TGF- $\beta$, however, attenuated the activation of NF- $\kappa B$ and upregulation of IL-1 mRNA levels, thus reducing production and release of proinflammatory cytokines [70]. Additionally, TGF- $\beta$ has been reported to function on the cellular level by decreasing the chemotactic activity of microglia [71].

\section{Anti-inflammatory regulation of $\mathrm{Hsp} 70$}

Heat Shock Proteins (Hsps) are evolutionarily conserved molecules that reduce brain injury. They have been divided into six major families, including Hsp100, Hsp90, Hsp70, Hsp60, Hsp40, and small Hsps. Among these, it has been reported that Hsp70 confers an anti-inflammatory effect through inhibition of both pro-inflammatory transcription factor NF-kB activation, and of ROS [72]. Hsp70 has been detected in neurons, astrocytes, microglia, and endothelial cells after brain infarction, and appeared in the context of a stroke model to function through direct association with NF-кB and ІкB, whereupon it prevents ІкB phosphorylation [73]. Other experimental findings that have helped to delineate the function of $\mathrm{Hsp} 70$ include that intracellular overexpression of Hsp70 decreases NF-kB activation in astrocytes [74]; overexpression in an experimental stroke model produced downregulation of TNF- $\alpha$ and IL-1 $\beta$ [75]; extracellular Hsp70 modulates immune responses [76]; and intravenous injection of Hsp70 in rat model reduced the volume of infarction produced by experimental stroke induction [77]. 


\section{POST-STROKE SUPPRESSION OF THE ADAPTIVE IMMUNE} SYSTEM

$\mathrm{T}$ cells are rapidly recruited to the ischemic brain within $24 \mathrm{~h}$ post-stroke, at which point they generally function to aggravate brain damage $[78,79]$. This is not invariably the case, however, as is illustrated by the Treg subset of T cells, which plays an important protective role in immunohomeostasis and the pathophysiology of ischemic stroke [80]. Treg cells accumulate within the ischemic hemisphere, spleen, and proximal and distal lymph nodes in experimental models of stroke [81], and Dolati et al. [82] demonstrated that Treg depletion may promote stroke. Conversely, the augmentation of Treg activity was shown to decrease both the volume of an experimentally-induced infarct, and subsequent post-stroke deficit [81]. There are many subpopulations of Tregs, including Th3, Trl, CD8 Tregs, natural killer Tregs, and $\mathrm{CD}^{+} \mathrm{CD} 25^{+} \mathrm{FoxP}^{+}$Tregs [83]. Among these, $\mathrm{CD} 4^{+} \mathrm{CD} 25^{+} \mathrm{FoxP}^{+}$ Tregs are the most well-characterized. $\mathrm{CD} 4{ }^{+} \mathrm{CD} 25^{+} \mathrm{FoxP}{ }^{+}$Tregs mainly arise from progenitor cells in the bone marrow and develop in the thymus through the processes of positive and negative selection (Fig. 2) [84]. CD $4^{+} \mathrm{CD} 25^{+} \mathrm{FoxP}^{+}$Tregs can be activated via $T$ cell receptors [85]. In the context of stroke, a growing body of evidence implicates $\mathrm{CD} 4{ }^{+} \mathrm{CD} 25^{+} \mathrm{FoxP} 3^{+}$Tregs as important neuroprotective immunomodulators, but the mechanism by which this effect proceeds remains unclear $[86,87]$. One experiment observed that, in mice, $\mathrm{CD} 4^{+} \mathrm{CD} 25^{+}$Tregs were beneficial to neuronal survival after an ischemic insult by modulating autoimmunity [88]. In another mouse study, these Tregs were reported to be associated with cocaine-and-amphetamine-regulated-transcript-mediated neuroprotection after stroke [89]. A third study, in this case performed on patients following acute ischemic stroke, reported both an increase of $\mathrm{CD} 4{ }^{+} \mathrm{CD} 25^{+} \mathrm{FoxP} 3^{+}$Tregs in the peripheral blood, and a reduction in the suppressive effects of these cells on T cell proliferation [90].

Another manner by which the function of Treg cells has been investigated is through their interactions with microglia. Foxp3, which functions as a repressor of microglial activation, plays an important role in reducing microglia-mediated neuroinflammation. Cerebral Foxp $3^{+}$Tregs were shown to inhibit the LPSinduced inflammatory response of microglia in vitro [91], while a Foxp3-mutation appeared to increase microglial release of proinflammatory factors, such as CXCL10 and MCP-1, in a mouse model [92]. Mechanistically, Tregs appear able to promote polarization of microglia toward an M2 phenotype accompanied by lowered IL-6 and TNF- $\alpha$ expression in vitro [93]. In summary, these experimental results demonstrate the beneficial consequences of Treg activation both in vitro and in vivo (Fig. 2).

Finally, yet another line of evidence involves programmed death-1 (PD-1), a T cell regulatory molecule with two ligands, PD-L1 and PD-L2. PD-L1 is widely expressed on T cells, B cells, monocytes, and dendritic cells (DCs); PD-L2 is located on macrophages, certain B cells, and DCs [94]. PD-L1 is expressed on

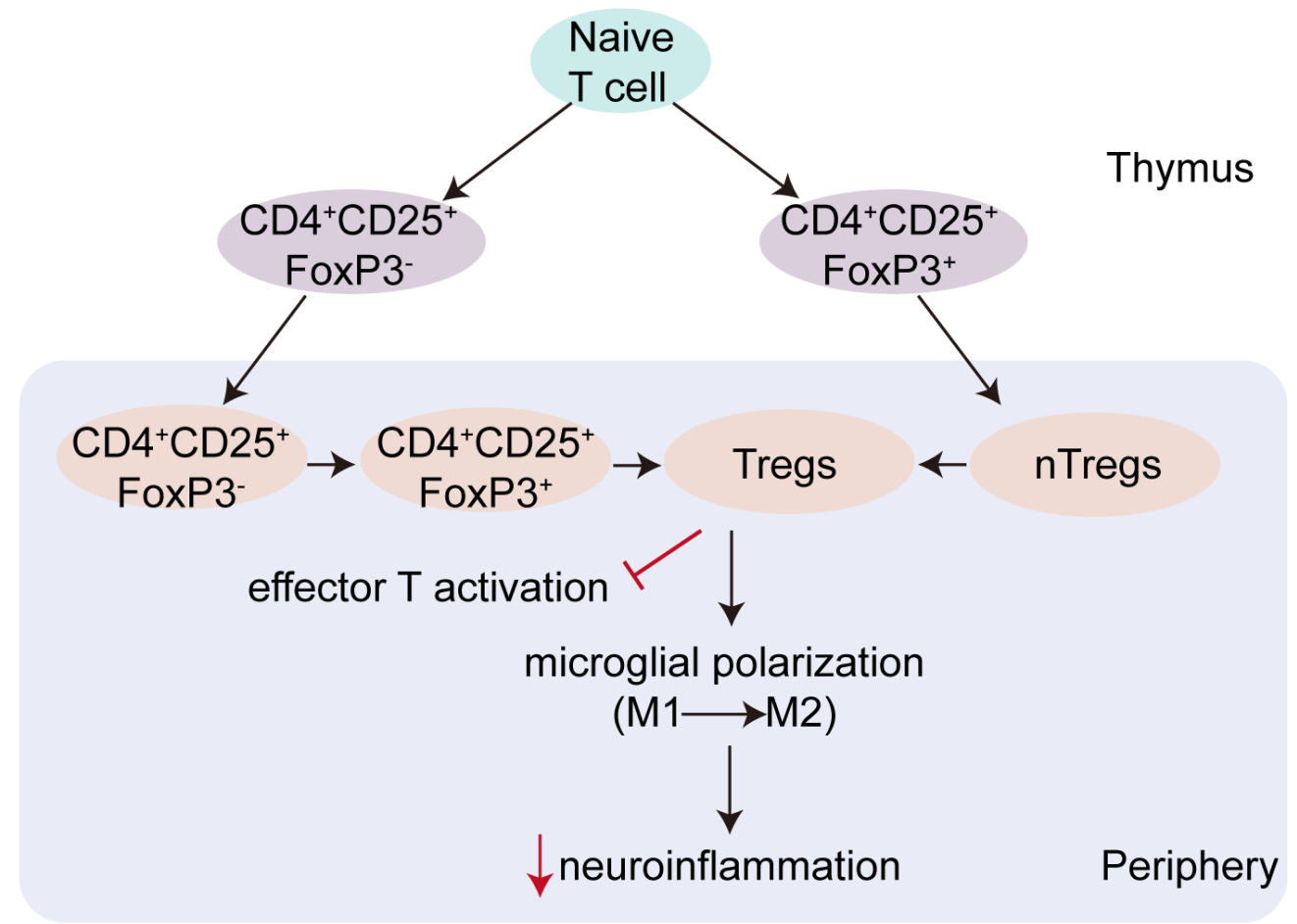

Fig. 2. The origin and function of Treg cells. CD $4^{+} \mathrm{CD} 25^{+}$ FoxP3 ${ }^{+}$Tregs mainly arise from progenitor cells in the bone marrow and develop in the thymus through the processes of positive and negative selection. $\mathrm{CD} 4^{+} \mathrm{CD} 25^{+}$FoxP $3^{+}$Tregs can limit activation of effector T cells. Tregs are also able to change the polarization of microglia and suppress excessive expression of neuroinflammatory mediators by microglia. 
Tregs and functions to inhibit the proliferation of T cells. Through inhibition of neutrophil MMP-9 expression, Treg-mediated PD-1/ PD-L1 interaction has been demonstrated to reduce brain damage after ischemic stroke [95].

\section{NEUROIMMUNOMODULATION}

Communication between the immune and nervous systems is essential in host defense against inflammatory diseases. There is a growing body of evidence confirming that neuroendocrine pathways, such as the hypothalamopituitary-adrenal (HPA) axis and the sympathetic division of the autonomic nervous system (SNS), act as anti-inflammatory balancing mechanisms to regulate the inflammatory response $[12,96,97]$. Neurohormonal negative regulation of immune function by the HPA axis has been widely studied [98]. HPA axis activation results in the release of glucocorticoids, which exert their manifold effects on many different effec- tors through their action on transcription-modulating intracellular receptors. In immune cells such as macrophages, neutrophils, $\mathrm{T}$ cells, and $\mathrm{B}$ cells, cortisol is a potent anti-inflammatory molecule that acts to downregulate the production of pro-inflammatory cytokines through interaction with the NF- $\mathrm{kB}$ transcription factor that controls the production of these cytokines [99]. The SNS has been shown to possess both pro- and anti-inflammatory potential [100]. All lymphoid organs receive input from postganglionic sympathetic neurons; norepinephrine released through the termini of these nerves regulates the activity of the cellular effectors of immune function. Catecholamines released through this pathway bind to receptors (primarily the $\beta_{2}$ adrenergic receptor) on the surface of the cellular effectors of immunity, whereupon they act through intracellular signaling cascades to influence gene expression relevant to the regulation of immune responses [101]. It has been suggested that cocaine- and amphetamine-regulated transcript-mediated neuroprotection may occur through SNS

Table 1. Immunosuppression mechanisms studied in stroke

References

Innate immune system
TAM/Gas6
Anti-inflammatory mediato
IL-1 receptor antagonist
IL-10
TGF- $\beta$
Adaptive immune system
Regulatory T cells (Tregs)

Adaptive immune system
Regulatory T cells (Tregs)
Neuro-immunomodulation
HPA axis
SNS
Cholinergic anti-inflammatory pathway
a7 nAChRs

rGas6 reduced brain injury via inhibition of the TLR/TRAF/NF-кB pathway

IL-1Ra has been used safely for ischemic stroke in Phase II trials

[55]

IL-1Ra promotes neuroprotection

IL-10 promotes neuronal survival and inhibits inflammatory responses

$[20]$

$[57]$

IL- $10^{-/-}$mice have increased infarct volumes $24 \mathrm{~h}$ after stroke

$[61]$

TGF- $\beta$ knockout aggravates brain damage

TGF- $\beta$ overexpression decreases the inflammatory response and reduces brain injury

[68]

[69] in mice subjected to $\mathrm{MCAO}$

$\mathrm{CD} 4{ }^{+} \mathrm{CD} 25^{+}$Tregs may be beneficial to neuronal survival

$\mathrm{CD} 4^{+} \mathrm{CD} 25^{+}$Tregs could facilitate cocaine-and-amphetamine-regulated-transcriptmediated neuroprotection after stroke

Increased $\mathrm{CD}^{+} \mathrm{CD} 25^{+} \mathrm{FoxP} 3^{+}$Tregs in the peripheral blood reduced $\mathrm{T}$ cell proliferation in patients with acute ischemic stroke

Tregs reduced brain damage after ischemic stroke by mediating PD-1/PD-L1 interaction

The HPA axis participates in negative neurohormonal regulation

The cholinergic anti-inflammatory pathway inhibits the release of cytokines and promotes neuroprotection

Treatment with the selective $a 7 \mathrm{nAChR}$ agonist PHA 568487 was found to be associated with a decrease in the number of microglia expressing the M1 phenotype in a pMCAO model

TLR, Toll-like receptor; TAM, Tyro3/Axl/MerTK; DAMP, Damage associated molecular pattern; Gas6, Growth arrest-specific 6; SOCS 1, Suppressor of cytokine signaling 1; SAH, Subarachnoid hemorrhage; Hsp70, Heat shock protein 70; IL-10, Interleukin-10; TGF- $\beta$, Transforming growth factor $\beta$; CSF, Cerebrospinal fluid; BBB, Blood brain barrier; SNS, Sympathetic nervous system; HPA, Hypothalamopituitary-adrenal; LRRs, Leucine-rich repeats; TIR, Toll/IL-1 receptor; MyD88, Myeloid differentiation protein 88; TRIF, TIR domain-containing adaptor inducing interferon $\beta$; NF-kB, Nuclear factor kappa B; LPS, Lipopolysaccharide; MCAO, Middle cerebral artery occlusion; IL-1, Interleukin-1; IL-1Ra, Interleukin-1 receptor antagonist; Tregs, Regulatory T cells; PD-1, Programmed death 1; MMP-9, Matrix metalloproteinase 9; DC, Dendritic cell; Th3, T helper 3 cell; Trl, Type 1 regulatory T cell; TNF- $\alpha$, Tumor necrosis factor alpha. 
regulation [89]. Down-regulation of inflammation by the SNS proceeds mainly through $\beta$-adrenoceptors. One study addressed the relevance of this mechanism to stroke pathogenesis by reporting that stroke-induced activation of the SNS results in the secretion of catecholamines, causing a $\beta$-adrenergic receptor-mediated reduction in TNF- $\alpha$ and concomitant promotion of IL-10 production [102].

The cholinergic anti-inflammatory pathway is classified as a neuro-immunomodulatory pathway [103]. As compared to the neuroendocrine mechanisms mentioned above, neuro-immunomodulation is distinguished by its rapid action. When pro-inflammatory cytokines are released after immune response activation, sensory vagal afferents and regulatory vagal efferents form an inflammatory reflex arc that continuously monitors the response [104]. The cholinergic anti-inflammatory pathway can be activated in this setting to counteract the release of excessive TNF- $\alpha$; the ability of this pathway to inhibit the release of cytokines has been shown to promote neuroprotection [105]. The central function of the pathway may be mediated through stimulation of the $a 7 \mathrm{nACh}$ receptors ( $\alpha 7 \mathrm{nAChRs)} \mathrm{responsible} \mathrm{for} \mathrm{microglial} \mathrm{activation:} \mathrm{intra-}$ peritoneal injection of PNU-120596, an allosteric modulator of a7 nAChRs, decreased infarct size and improved neurological tests results in a mouse MCAO model [106, 107]. Subsequent work confirmed that intranasal administration of PNU-120596 produced a similar therapeutic effect in a rat model [108]. Likewise, treatment with the selective $\alpha 7 \mathrm{nAChR}$ agonist PHA 568487 was found to be associated with a decrease in the number of microglia expressing the $\mathrm{M} 1$ phenotype and an increase in number of $\mathrm{M} 2$ microglia in a pMCAO model [109]. PHA 568487 administration was also found to reduce brain injury after experimental stroke in rodents [110].

\section{CONCLUSION}

The inflammatory response, by disrupting immunohomeostasis and aggravating brain damage, constitutes a major contributory factor to the pathobiology of stroke. Previous studies have highlighted the neuroprotective effects of immunosuppression, which is achievable through both innate and adaptive mechanisms. Various regulatory pathways, such as the TAM/Gas6 pathway, have been shown to be involved in modulating post-stroke inflammation, and therefore in the reduction of post-stroke brain injury. Furthermore, a growing body of research describes the use of anti-inflammatory regulators such as IL-1Ra in clinical trials for ischemic stroke. In addition to the traditional immunosuppressive molecules, $\mathrm{CD} 4^{+} \mathrm{CD} 25^{+} \mathrm{FoxP}^{+}$Tregs play a unique protective role in stroke pathogenesis. Treg-mediated immunoregulation following stroke should be a focus of future research. Finally, the cholinergic anti-inflammatory pathway provides an additional target for post-stroke pharmacologic intervention. Taken together, these findings (Table 1) lead us to conclude that immunoregulation may provide a promising approach both to the study of stroke pathophysiology, and to the discovery of treatments that limit the destructive effects of cerebrovascular disease.

\section{CONFLICT OF INTEREST}

The authors declare no conflict of interests.

\section{FUNDING}

This work was partially supported by the National Nature Science Foundation of China (no. 81871838 and 82072549); the Science and Technology Plan of Beijing Tongzhou District (KJ2020CX002); and the Beijing Tongzhou District Financial Fund.

\section{REFERENCES}

1. Chandra A, Stone CR, Du X, Li WA, Huber M, Bremer R, Geng X, Ding Y (2017) The cerebral circulation and cerebrovascular disease III: stroke. Brain Circ 3:66-77.

2. Liu Y, Wang Y, Li WA, Yan A, Wang Y (2017) Validation of the Essen Stroke Risk Score in different subtypes of ischemic stroke. Neurol Res 39:504-508.

3. Fu Y, Liu Q, Anrather J, Shi FD (2015) Immune interventions in stroke. Nat Rev Neurol 11:524-535.

4. Zhang Z, Zhang L, Ding Y, Han Z, Ji X (2018) Effects of therapeutic hypothermia combined with other neuroprotective strategies on ischemic stroke: review of evidence. Aging Dis 9:507-522.

5. Shetty AK, Upadhya R, Madhu LN, Kodali M (2019) Novel insights on systemic and brain aging, stroke, amyotrophic lateral sclerosis, and Alzheimer's disease. Aging Dis 10:470-482.

6. Liu M, Liu J, Zhang L, Xu W, He D, Wei W, Ge Y, Dandu C (2020) An evidence of brain-heart disorder: mental stressinduced myocardial ischemia regulated by inflammatory cytokines. Neurol Res 42:670-675.

7. Dirnagl U (2012) Pathobiology of injury after stroke: the neurovascular unit and beyond. Ann NY Acad Sci 1268:21-25.

8. Li W, Yang S (2016) Targeting oxidative stress for the treatment of ischemic stroke: upstream and downstream therapeutic strategies. Brain Circ 2:153-163.

9. Mracsko E, Veltkamp R (2014) Neuroinflammation after in- 
tracerebral hemorrhage. Front Cell Neurosci 8:388.

10. Fang M, Zhong L, Jin X, Cui R, Yang W, Gao S, Lv J, Li B, Liu T (2019) Effect of inflammation on the process of stroke rehabilitation and poststroke depression. Front Psychiatry 10:184.

11. Cronkite DA, Strutt TM (2018) The regulation of inflammation by innate and adaptive lymphocytes. J Immunol Res 2018:1467538.

12. Schimmel SJ, Acosta S, Lozano D (2017) Neuroinflammation in traumatic brain injury: a chronic response to an acute injury. Brain Circ 3:135-142.

13. Chamorro Á, Meisel A, Planas AM, Urra X, van de Beek D, Veltkamp R (2012) The immunology of acute stroke. Nat Rev Neurol 8:401-410.

14. Wang Y, Ge P, Zhu Y (2013) TLR2 and TLR4 in the brain injury caused by cerebral ischemia and reperfusion. Mediators Inflamm 2013:124614.

15. Kumar V (2019) Toll-like receptors in the pathogenesis of neuroinflammation. J Neuroimmunol 332:16-30.

16. Amantea D, Micieli G, Tassorelli C, Cuartero MI, Ballesteros I, Certo M, Moro MA, Lizasoain I, Bagetta G (2015) Rational modulation of the innate immune system for neuroprotection in ischemic stroke. Front Neurosci 9:147.

17. Zhang C, Zhu Y, Wang S, Zachory Wei Z, Jiang MQ, Zhang Y, Pan Y, Tao S, Li J, Wei L (2018) Temporal gene expression profiles after focal cerebral ischemia in mice. Aging Dis 9:249-261.

18. Shen F, Jiang L, Han F, Degos V, Chen S, Su H (2019) Increased inflammatory response in old mice is associated with more severe neuronal injury at the acute stage of ischemic stroke. Aging Dis 10:12-22.

19. Rothlin CV, Carrera-Silva EA, Bosurgi L, Ghosh S (2015) TAM receptor signaling in immune homeostasis. Annu Rev Immunol 33:355-391.

20. Lee JH, Kam EH, Kim JM, Kim SY, Kim EJ, Cheon SY, Koo BN (2017) Intranasal administration of interleukin-1 receptor antagonist in a transient focal cerebral ischemia rat model. Biomol Ther (Seoul) 25:149-157.

21. Clausen BH, Lambertsen KL, Dagnæs-Hansen F, Babcock AA, von Linstow CU, Meldgaard M, Kristensen BW, Deierborg T, Finsen B (2016) Cell therapy centered on IL-1Ra is neuroprotective in experimental stroke. Acta Neuropathol 131:775-791.

22. Nakajima M, Nito C, Sowa K, Suda S, Nishiyama Y, Nakamura-Takahashi A, Nitahara-Kasahara Y, Imagawa K, Hirato T, Ueda M, Kimura K, Okada T (2017) Mesenchymal stem cells overexpressing interleukin-10 promote neuroprotection in experimental acute ischemic stroke. Mol Ther Methods Clin Dev 6:102-111.
23. Cramer JV, Benakis C, Liesz A (2019) T cells in the postischemic brain: troopers or paramedics? J Neuroimmunol 326:33-37.

24. Mracsko E, Liesz A, Karcher S, Zorn M, Bari F, Veltkamp R (2014) Differential effects of sympathetic nervous system and hypothalamic-pituitary-adrenal axis on systemic immune cells after severe experimental stroke. Brain Behav Immun 41:200-209.

25. Sauter IP, Madrid KG, de Assis JB, Sá-Nunes A, Torrecilhas AC, Staquicini DI, Pasqualini R, Arap W, Cortez M (2019) TLR9/MyD88/TRIF signaling activates host immune inhibitory CD200 in Leishmania infection. JCI Insight 4:e126207.

26. Fan X, Elkin K, Shi Y, Zhang Z, Cheng Y, Gu J, Liang J, Wang C, Ji X (2020) Schisandrin B improves cerebral ischemia and reduces reperfusion injury in rats through TLR4/NF- $\kappa$ B signaling pathway inhibition. Neurol Res 42:693-702.

27. Tajalli-Nezhad S, Karimian M, Beyer C, Atlasi MA, Azami Tameh A (2019) The regulatory role of Toll-like receptors after ischemic stroke: neurosteroids as TLR modulators with the focus on TLR2/4. Cell Mol Life Sci 76:523-537.

28. Brea D, Blanco M, Ramos-Cabrer P, Moldes O, Arias S, PérezMato M, Leira R, Sobrino T, Castillo J (2011) Toll-like receptors 2 and 4 in ischemic stroke: outcome and therapeutic values. J Cereb Blood Flow Metab 31:1424-1431.

29. McShane L, Tabas I, Lemke G, Kurowska-Stolarska M, Maffia P (2019) TAM receptors in cardiovascular disease. Cardiovasc Res 115:1286-1295.

30. Lee CH, Chun T (2019) Anti-inflammatory role of TAM family of receptor tyrosine kinases via modulating macrophage function. Mol Cells 42:1-7.

31. Banerjee S, Halder K, Bose A, Bhattacharya P, Gupta G, Karmahapatra S, Das S, Chaudhuri S, Bhattacharyya Majumdar S, Majumdar S (2011) TLR signaling-mediated differential histone modification at IL-10 and IL-12 promoter region leads to functional impairments in tumor-associated macrophages. Carcinogenesis 32:1789-1797.

32. Hally K, Fauteux-Daniel S, Hamzeh-Cognasse H, Larsen P, Cognasse F (2020) Revisiting platelets and toll-like receptors (TLRs): at the interface of vascular immunity and thrombosis. Int J Mol Sci 21:6150.

33. van der Meer JH, van der Poll T, van 't Veer C (2014) TAM receptors, Gas6, and protein S: roles in inflammation and hemostasis. Blood 123:2460-2469.

34. Blades F, Aprico A, Akkermann R, Ellis S, Binder MD, Kilpatrick TJ (2018) The TAM receptor TYRO3 is a critical regulator of myelin thickness in the central nervous system. Glia 66:2209-2220. 
35. Shafit-Zagardo B, Gruber RC, DuBois JC (2018) The role of TAM family receptors and ligands in the nervous system: from development to pathobiology. Pharmacol Ther 188:97117.

36. Lu Q, Lemke G (2001) Homeostatic regulation of the immune system by receptor tyrosine kinases of the Tyro 3 family. Science 293:306-311.

37. Sun B, Qi N, Shang T, Wu H, Deng T, Han D (2010) Sertoli cell-initiated testicular innate immune response through tolllike receptor-3 activation is negatively regulated by Tyro3, Axl, and mer receptors. Endocrinology 151:2886-2897.

38. Campbell BCV, Mitchell PJ, Churilov L, Keshtkaran M, Hong KS, Kleinig TJ, Dewey HM, Yassi N, Yan B, Dowling RJ, Parsons MW, Wu TY, Brooks M, Simpson MA, Miteff F, Levi CR, Krause M, Harrington TJ, Faulder KC, Steinfort BS, Ang T, Scroop R, Barber PA, McGuinness B, Wijeratne T, Phan TG, Chong W, Chandra RV, Bladin CF, Rice H, de Villiers L, Ma H, Desmond PM, Meretoja A, Cadilhac DA, Donnan GA, Davis SM; EXTEND-IA Investigators (2017) Endovascular thrombectomy for ischemic stroke increases disability-free survival, quality of life, and life expectancy and reduces cost. Front Neurol 8:657.

39. Wu G, McBride DW, Zhang JH (2018) Axl activation attenuates neuroinflammation by inhibiting the TLR/TRAF/NF- $\kappa$ B pathway after MCAO in rats. Neurobiol Dis 110:59-67.

40. Zheng Y, Zhu G, He J, Wang G, Li D, Zhang F (2019) Icariin targets Nrf2 signaling to inhibit microglia-mediated neuroinflammation. Int Immunopharmacol 73:304-311.

41. Ji R, Meng L, Li Q, Lu Q (2015) TAM receptor deficiency affects adult hippocampal neurogenesis. Metab Brain Dis 30:633-644.

42. Tondo G, Perani D, Comi C (2019) TAM receptor pathways at the crossroads of neuroinflammation and neurodegeneration. Dis Markers 2019:2387614.

43. Ji R, Tian S, Lu HJ, Lu Q, Zheng Y, Wang X, Ding J, Li Q, Lu Q (2013) TAM receptors affect adult brain neurogenesis by negative regulation of microglial cell activation. J Immunol 191:6165-6177.

44. Zagórska A, Través PG, Lew ED, Dransfield I, Lemke G (2014) Diversification of TAM receptor tyrosine kinase function. Nat Immunol 15:920-928.

45. Saijo K, Winner B, Carson CT, Collier JG, Boyer L, Rosenfeld MG, Gage FH, Glass CK (2009) A Nurr1/CoREST pathway in microglia and astrocytes protects dopaminergic neurons from inflammation-induced death. Cell 137:47-59.

46. Goudarzi S, Gilchrist SE, Hafizi S (2020) Gas6 induces myelination through anti-inflammatory IL-10 and TGF- $\beta$ up- regulation in white matter and glia. Cells 9:1779.

47. Woiciechowsky C, Schöning B, Stoltenburg-Didinger G, Stockhammer F, Volk HD (2004) Brain-IL-1 beta triggers astrogliosis through induction of IL-6: inhibition by propranolol and IL-10. Med Sci Monit 10:BR325-BR330.

48. O'Carroll SJ, Kho DT, Wiltshire R, Nelson V, Rotimi O, Johnson R, Angel CE, Graham ES (2015) Pro-inflammatory TNFa and IL- $1 \beta$ differentially regulate the inflammatory phenotype of brain microvascular endothelial cells. J Neuroinflammation 12:131.

49. Kozak HH, Uğuz F, Kılınç İ, Uca AU, Tokgöz OS, Güney F, Özer N (2019) A cross-sectional study to assess the association between major depression and inflammatory markers in patients with acute ischemic stroke. Indian J Psychiatry 61:283-289.

50. Burrows F, Haley MJ, Scott E, Coutts G, Lawrence CB, Allan SM, Schiessl I (2016) Systemic inflammation affects reperfusion following transient cerebral ischaemia. Exp Neurol 277:252-260.

51. Eisenhut M (2018) In diabetic ketoacidosis brain injury including cerebral oedema and infarction is caused by interleukin-1. Med Hypotheses 121:44-46.

52. Greenhalgh AD, Brough D, Robinson EM, Girard S, Rothwell NJ, Allan SM (2012) Interleukin-1 receptor antagonist is beneficial after subarachnoid haemorrhage in rat by blocking haem-driven inflammatory pathology. Dis Model Mech 5:823-833.

53. Singh N, Hopkins SJ, Hulme S, Galea JP, Hoadley M, Vail A, Hutchinson PJ, Grainger S, Rothwell NJ, King AT, Tyrrell PJ (2014) The effect of intravenous interleukin-1 receptor antagonist on inflammatory mediators in cerebrospinal fluid after subarachnoid haemorrhage: a phase II randomised controlled trial. J Neuroinflammation 11:1.

54. Pradillo JM, Murray KN, Coutts GA, Moraga A, Oroz-Gonjar F, Boutin H, Moro MA, Lizasoain I, Rothwell NJ, Allan SM (2017) Reparative effects of interleukin-1 receptor antagonist in young and aged/co-morbid rodents after cerebral ischemia. Brain Behav Immun 61:117-126.

55. Emsley HC, Smith CJ, Georgiou RF, Vail A, Hopkins SJ, Rothwell NJ, Tyrrell PJ; Acute Stroke Investigators (2005) A randomised phase II study of interleukin-1 receptor antagonist in acute stroke patients. J Neurol Neurosurg Psychiatry 76:1366-1372.

56. Smith CJ, Hulme S, Vail A, Heal C, Parry-Jones AR, Scarth S, Hopkins K, Hoadley M, Allan SM, Rothwell NJ, Hopkins SJ, Tyrrell PJ (2018) SCIL-stroke (subcutaneous interleukin-1 receptor antagonist in ischemic stroke): a randomized con- 
trolled phase 2 trial. Stroke 49:1210-1216.

57. Strle K, Zhou JH, Shen WH, Broussard SR, Johnson RW, Freund GG, Dantzer R, Kelley KW (2001) Interleukin-10 in the brain. Crit Rev Immunol 21:427-449.

58. Garcia JM, Stillings SA, Leclerc JL, Phillips H, Edwards NJ, Robicsek SA, Hoh BL, Blackburn S, Doré S (2017) Role of interleukin-10 in acute brain injuries. Front Neurol 8:244.

59. Cherry JD, Olschowka JA, O’Banion MK (2014) Neuroinflammation and M2 microglia: the good, the bad, and the inflamed. J Neuroinflammation 11:98.

60. Kawabori M, Yenari MA (2015) Inflammatory responses in brain ischemia. Curr Med Chem 22:1258-1277.

61. Grilli M, Barbieri I, Basudev H, Brusa R, Casati C, Lozza G, Ongini E (2000) Interleukin-10 modulates neuronal threshold of vulnerability to ischaemic damage. Eur J Neurosci 12:2265-2272.

62. Spera PA, Ellison JA, Feuerstein GZ, Barone FC (1998) IL-10 reduces rat brain injury following focal stroke. Neurosci Lett 251:189-192.

63. Bodhankar S, Chen Y, Vandenbark AA, Murphy SJ, Offner H (2013) IL-10-producing B-cells limit CNS inflammation and infarct volume in experimental stroke. Metab Brain Dis 28:375-386.

64. Liu X, Li Q, Zhu R, He Z (2017) Association of IL-10-1082A/ G polymorphism with ischemic stroke: evidence from a casecontrol study to an updated meta-analysis. Genet Test Mol Biomarkers 21:341-350.

65. Liesz A, Bauer A, Hoheisel JD, Veltkamp R (2014) Intracerebral interleukin-10 injection modulates post-ischemic neuroinflammation: an experimental microarray study. Neurosci Lett 579:18-23.

66. Munshi A, Rajeshwar K, Kaul S, Al-Hazzani A, Alshatwi AA, Sai Babu M, Usha A, Jyothy A (2010) Interleukin-10-1082 promoter polymorphism and ischemic stroke risk in a South Indian population. Cytokine 52:221-224.

67. Arponen O, Muuronen A, Taina M, Sipola P, Hedman M, Jäkälä P, Vanninen R, Pulkki K, Mustonen P (2015) Acute phase IL-10 plasma concentration associates with the high risk sources of cardiogenic stroke. PLoS One 10:e120910.

68. Hayashi Y, Mikawa S, Ogawa C, Masumoto K, Katou F, Sato K (2019) BMP6 expression in the adult rat central nervous system. J Chem Neuroanat 98:41-54.

69. Pang L, Ye W, Che XM, Roessler BJ, Betz AL, Yang GY (2001) Reduction of inflammatory response in the mouse brain with adenoviral-mediated transforming growth factor-ss 1 expression. Stroke 32:544-552.

70. Toma I, McCaffrey TA (2012) Transforming growth factor- $\beta$ and atherosclerosis: interwoven atherogenic and atheroprotective aspects. Cell Tissue Res 347:155-175.

71. Huang WC, Yen FC, Shie FS, Pan CM, Shiao YJ, Yang CN, Huang FL, Sung YJ, Tsay HJ (2010) TGF-betal blockade of microglial chemotaxis toward Abeta aggregates involves SMAD signaling and down-regulation of CCL5. J Neuroinflammation 7:28.

72. Mohammadi F, Nezafat N, Negahdaripour M, Dabbagh F, Haghghi AB, Kianpour S, Banihashemi M, Ghasemi Y (2018) Neuroprotective effects of heat shock protein70. CNS Neurol Disord Drug Targets 17:736-742.

73. Kim JY, Kim JW, Yenari MA (2020) Heat shock protein signaling in brain ischemia and injury. Neurosci Lett 715:134642.

74. Kim JY, Han Y, Lee JE, Yenari MA (2018) The 70-kDa heat shock protein (Hsp70) as a therapeutic target for stroke. Expert Opin Ther Targets 22:191-199.

75. Kim JY, Yenari MA (2013) The immune modulating properties of the heat shock proteins after brain injury. Anat Cell Biol 46:1-7.

76. Giffard RG, Han RQ, Emery JF, Duan M, Pittet JF (2008) Regulation of apoptotic and inflammatory cell signaling in cerebral ischemia: the complex roles of heat shock protein 70 . Anesthesiology 109:339-348.

77. Shevtsov MA, Nikolaev BP, Yakovleva LY, Dobrodumov AV, Dayneko AS, Shmonin AA, Vlasov TD, Melnikova EV, Vilisov AD, Guzhova IV, Ischenko AM, Mikhrina AL, Galibin OV, Yakovenko IV, Margulis BA (2014) Neurotherapeutic activity of the recombinant heat shock protein Hsp70 in a model of focal cerebral ischemia in rats. Drug Des Devel Ther 8:639650.

78. Gelderblom M, Leypoldt F, Steinbach K, Behrens D, Choe CU, Siler DA, Arumugam TV, Orthey E, Gerloff C, Tolosa E, Magnus T (2009) Temporal and spatial dynamics of cerebral immune cell accumulation in stroke. Stroke 40:1849-1857.

79. Nakamura K, Shichita T (2019) Cellular and molecular mechanisms of sterile inflammation in ischaemic stroke. J Biochem 165:459-464.

80. Ito M, Komai K, Mise-Omata S, Iizuka-Koga M, Noguchi Y, Kondo T, Sakai R, Matsuo K, Nakayama T, Yoshie O, Nakatsukasa H, Chikuma S, Shichita T, Yoshimura A (2019) Brain regulatory $\mathrm{T}$ cells suppress astrogliosis and potentiate neurological recovery. Nature 565:246-250.

81. Duffy SS, Keating BA, Perera CJ, Moalem-Taylor G (2018) The role of regulatory $\mathrm{T}$ cells in nervous system pathologies. J Neurosci Res 96:951-968.

82. Dolati S, Ahmadi M, Khalili M, Taheraghdam AA, Siahmansouri H, Babaloo Z, Aghebati-Maleki L, Jadidi-Niaragh F, 
Younesi V, Yousefi M (2018) Peripheral Th17/Treg imbalance in elderly patients with ischemic stroke. Neurol Sci 39:647654.

83. Hori S, Nomura T, Sakaguchi S (2003) Control of regulatory $\mathrm{T}$ cell development by the transcription factor Foxp3. Science 299:1057-1061.

84. Tanoue T, Atarashi K, Honda K (2016) Development and maintenance of intestinal regulatory T cells. Nat Rev Immunol 16:295-309.

85. Chen S, Wu H, Klebe D, Hong Y, Zhang J, Tang J (2013) Regulatory $\mathrm{T}$ cell in stroke: a new paradigm for immune regulation. Clin Dev Immunol 2013:689827.

86. Kleinschnitz C, Kraft P, Dreykluft A, Hagedorn I, Göbel K, Schuhmann MK, Langhauser F, Helluy X, Schwarz T, Bittner S, Mayer CT, Brede M, Varallyay C, Pham M, Bendszus M, Jakob P, Magnus T, Meuth SG, Iwakura Y, Zernecke A, Sparwasser T, Nieswandt B, Stoll G, Wiendl H (2013) Regulatory T cells are strong promoters of acute ischemic stroke in mice by inducing dysfunction of the cerebral microvasculature. Blood 121:679-691.

87. Ren X, Akiyoshi K, Vandenbark AA, Hurn PD, Offner H (2011) CD4+FoxP3+ regulatory T-cells in cerebral ischemic stroke. Metab Brain Dis 26:87-90.

88. Kipnis J, Mizrahi T, Hauben E, Shaked I, Shevach E, Schwartz M (2002) Neuroprotective autoimmunity: naturally occurring CD4+CD25+ regulatory T cells suppress the ability to withstand injury to the central nervous system. Proc Natl Acad Sci U S A 99:15620-15625.

89. Chang L, Chen Y, Li J, Liu Z, Wang Z, Chen J, Cao W, Xu Y (2011) Cocaine-and amphetamine-regulated transcript modulates peripheral immunity and protects against brain injury in experimental stroke. Brain Behav Immun 25:260-269.

90. Yan J, Read SJ, Henderson RD, Hull R, O'Sullivan JD, McCombe PA, Greer JM (2012) Frequency and function of regulatory $\mathrm{T}$ cells after ischaemic stroke in humans. J Neuroimmunol 243:89-94.

91. Xie L, Choudhury GR, Winters A, Yang SH, Jin K (2015) Cerebral regulatory $\mathrm{T}$ cells restrain microglia/macrophagemediated inflammatory responses via IL-10. Eur J Immunol 45:180-191.

92. Chung HS, Lee JH, Kim H, Lee HJ, Kim SH, Kwon HK, Im $\mathrm{SH}$, Bae H (2010) Foxp3 is a novel repressor of microglia activation. Glia 58:1247-1256.

93. Zhou K, Zhong Q, Wang YC, Xiong XY, Meng ZY, Zhao T, Zhu WY, Liao MF, Wu LR, Yang YR, Liu J, Duan CM, Li J, Gong QW, Liu L, Yang MH, Xiong A, Wang J, Yang QW (2017) Regulatory $\mathrm{T}$ cells ameliorate intracerebral hemorrhage-induced inflammatory injury by modulating microglia/macrophage polarization through the IL-10/GSK3 $\beta /$ PTEN axis. J Cereb Blood Flow Metab 37:967-979.

94. Charidimou A, Karayiannis C, Song TJ, Orken DN, Thijs V, Lemmens R, Kim J, Goh SM, Phan TG, Soufan C, Chandra RV, Slater LA, Haji S, Mok V, Horstmann S, Leung KT, Kawamura Y, Sato N, Hasebe N, Saito T, Wong LKS, Soo Y, Veltkamp R, Flemming KD, Imaizumi T, Srikanth V, Heo JH; International META-MICROBLEEDS Initiative (2017) Brain microbleeds, anticoagulation, and hemorrhage risk: metaanalysis in stroke patients with AF. Neurology 89:2317-2326.

95. Li P, Mao L, Liu X, Gan Y, Zheng J, Thomson AW, Gao Y, Chen J, Hu X (2014) Essential role of program death 1-ligand 1 in regulatory T-cell-afforded protection against blood-brain barrier damage after stroke. Stroke 45:857-864.

96. Bonaz B, Sinniger V, Pellissier S (2016) Anti-inflammatory properties of the vagus nerve: potential therapeutic implications of vagus nerve stimulation. J Physiol 594:5781-5790.

97. Mehta T, Hussain M, Sheth K, Ding Y, McCullough LD (2017) Risk of hemorrhagic transformation after ischemic stroke in patients with antiphospholipid antibody syndrome. Neurol Res 39:477-483.

98. Webster JI, Tonelli L, Sternberg EM (2002) Neuroendocrine regulation of immunity. Annu Rev Immunol 20:125-163.

99. Irwin MR, Cole SW (2011) Reciprocal regulation of the neural and innate immune systems. Nat Rev Immunol 11:625632.

100. Elenkov IJ, Wilder RL, Chrousos GP, Vizi ES (2000) The sympathetic nerve--an integrative interface between two supersystems: the brain and the immune system. Pharmacol Rev 52:595-638.

101. Nance DM, Sanders VM (2007) Autonomic innervation and regulation of the immune system (1987-2007). Brain Behav Immun 21:736-745.

102. Anne M, Juha K, Timo M, Mikko T, Olli V, Kyösti S, Heikki H, Vilho M (2007) Neurohormonal activation in ischemic stroke: effects of acute phase disturbances on long-term mortality. Curr Neurovasc Res 4:170-175.

103. Duris K, Lipkova J, Jurajda M (2017) Cholinergic anti-inflammatory pathway and stroke. Curr Drug Deliv 14:449-457.

104. Tracey KJ (2002) The inflammatory reflex. Nature 420:853859.

105. Lehner KR, Silverman HA, Addorisio ME, Roy A, Al-Onaizi MA, Levine Y, Olofsson PS, Chavan SS, Gros R, Nathanson NM, Al-Abed Y, Metz CN, Prado VF, Prado MAM, Tracey KJ, Pavlov VA (2019) Forebrain cholinergic signaling regulates innate immune responses and inflammation. Front Immunol 
10:585.

106. Jagdmann S, Dames C, Berchtold D, Winek K, Weitbrecht L, Meisel A, Meisel C (2020) Impact of key nicotinic AChR subunits on post-stroke pneumococcal pneumonia. Vaccines (Basel) 8:253.

107. Sun F, Jin K, Uteshev VV (2013) A type-II positive allosteric modulator of $\alpha 7 \mathrm{nAChRs}$ reduces brain injury and improves neurological function after focal cerebral ischemia in rats. PLoS One 8:e73581.

108. Sun F, Johnson SR, Jin K, Uteshev VV (2017) Boosting en- dogenous resistance of brain to ischemia. Mol Neurobiol 54:2045-2059.

109. Hoover DB (2017) Cholinergic modulation of the immune system presents new approaches for treating inflammation. Pharmacol Ther 179:1-16.

110. Colás L, Domercq M, Ramos-Cabrer P, Palma A, GómezVallejo V, Padro D, Plaza-García S, Pulagam KR, Higuchi M, Matute C, Llop J, Martín A (2018) In vivo imaging of A7 nicotinic receptors as a novel method to monitor neuroinflammation after cerebral ischemia. Glia 66:1611-1624. 